\title{
Upper mantle imaging beneath the Japan Islands by Hi-net tiltmeter recordings
}

\author{
Takashi Tonegawa ${ }^{1}$, Kazuro Hirahara ${ }^{2}$, Takuo Shibutani ${ }^{3}$, and Katsuhiko Shiomi ${ }^{4}$ \\ ${ }^{1}$ Department of Earth and Environmental Sciences, Graduate School of Environmental Studies, \\ Nagoya University, Furo-cho, Chikusa-ku, Nagoya 464-8602, Japan \\ ${ }^{2}$ Kyoto University, Kyoto, Japan \\ ${ }^{3}$ DPRI, Kyoto University, Uji, Japan \\ ${ }^{4}$ NIED, Tsukuba, Japan
}

(Received January 19, 2006; Revised April 5, 2006; Accepted April 25, 2006; Online published September 16, 2006)

\begin{abstract}
We present a novel receiver-function image of the upper mantle structure around the Japan subduction zone. To increase the amount of available waveform data containing the relatively lower frequency component, we examined whether the Hi-net tiltmeter recordings are usable for imaging the upper mantle discontinuities by comparing them with broadband seismograms in different frequency bands. We found that the two are comparable at a frequency band between 0.02 and $0.16 \mathrm{~Hz}$. To make receiver functions from tiltmeter data, stacked vertical components of broadband seismograms were used as source-time functions. Since such source-time functions may include biases from local structure, we also produced regional stacked source-time functions. The receiver function with the above frequency band does not seem to be affected by local structure. In the images derived from the receiver-function gathers, we were able to visualize both the oceanic Moho and the lower slab boundary, which could be traced down to depths of $400 \mathrm{~km}$ and $600 \mathrm{~km}$, respectively. These images also show an uplift of the $410-\mathrm{km}$ discontinuity and a depression of the $660-\mathrm{km}$ discontinuity in the regions that are probably affected by the cold subducting Pacific slab.
\end{abstract}

Key words: Receiver function, upper mantle, subducting slab, tiltmeter.

\section{Introduction}

Slab-induced depth variation of the seismic discontinuities in the upper mantle beneath the Japanese Islands has been well mapped by receiver function (RF) analysis based on broadband seismograms (see Li et al., 2000; Tonegawa et al., 2005). However, the density of broadband stations throughout the Japanese Islands is still too low (140 stations in Japan) to investigate the relation between the slab and the $410 \mathrm{~km}$ and $660 \mathrm{~km}$ upper mantle discontinuities (hereafter called the '410' and '660', respectively). These two discontinuities are observed globally with velocity jumps of several percentages, and are usually interpreted as mineral phase changes (Ringwood, 1975). In addition to the broadband stations, a high-density short-period network (Hi-net), which provides a highly sensitive observation of ground motion, has been deployed in the Japanese Islands by the National Research Institute for Earth Science and Disaster Prevention (NIED). Ramesh et al. (2005) found that the short-period recordings of the Hi-net stations include Ps phases from the mantle, and they successfully detected the 410 and the 660 beneath the Japanese Islands. However, Ps phases from the mantle are probably dominated by lower frequency signals of less than $1 \mathrm{~Hz}$. Since the dominant frequency of the Hi-net short-period station is around

Copyright (c) The Society of Geomagnetism and Earth, Planetary and Space Sciences (SGEPSS); The Seismological Society of Japan; The Volcanological Society of Japan; The Geodetic Society of Japan; The Japanese Society for Planetary Sciences; TERRAPUB.
$1 \mathrm{~Hz}$, it might be difficult to image the upper mantle discontinuities using these short-period data. The ideal setting for providing high-resolution receiver function images is a dense network that can record relatively lower frequency signals.

Cosited with the short-period sensors, NIED also deployed a high sensitivity accelerometer (hereafter called a tiltmeter) network for monitoring crustal deformation. Both Hori (2002) and Shiomi et al. (2003) suggested that the recordings of these tiltmeters could be used as broadband seismometers to disclose the structure of the upper mantle. If this were to be true, it may be possible to dramatically improve our knowledge of the dynamics of the upper mantle because we would be able to obtain a large quantity of available data that includes a sufficient number of lower frequency signals.

In this study, we examine whether these recordings are applicable for imaging the seismic discontinuities in the upper mantle. To calibrate tiltmeter recordings we first chose a closely located broadband station. We then compared the radial component waveforms (e.g. the amplitudes and the times of the peaks of phases following the direct $P$ wave) recorded by the two types of sensors from the same event in different frequency bands. Through this comparison we were able to identify a proper frequency band in which the two types of recordings show the greatest similarity. We then used the filtered tiltmeter data and constructed RF images of the upper mantle discontinuities. 


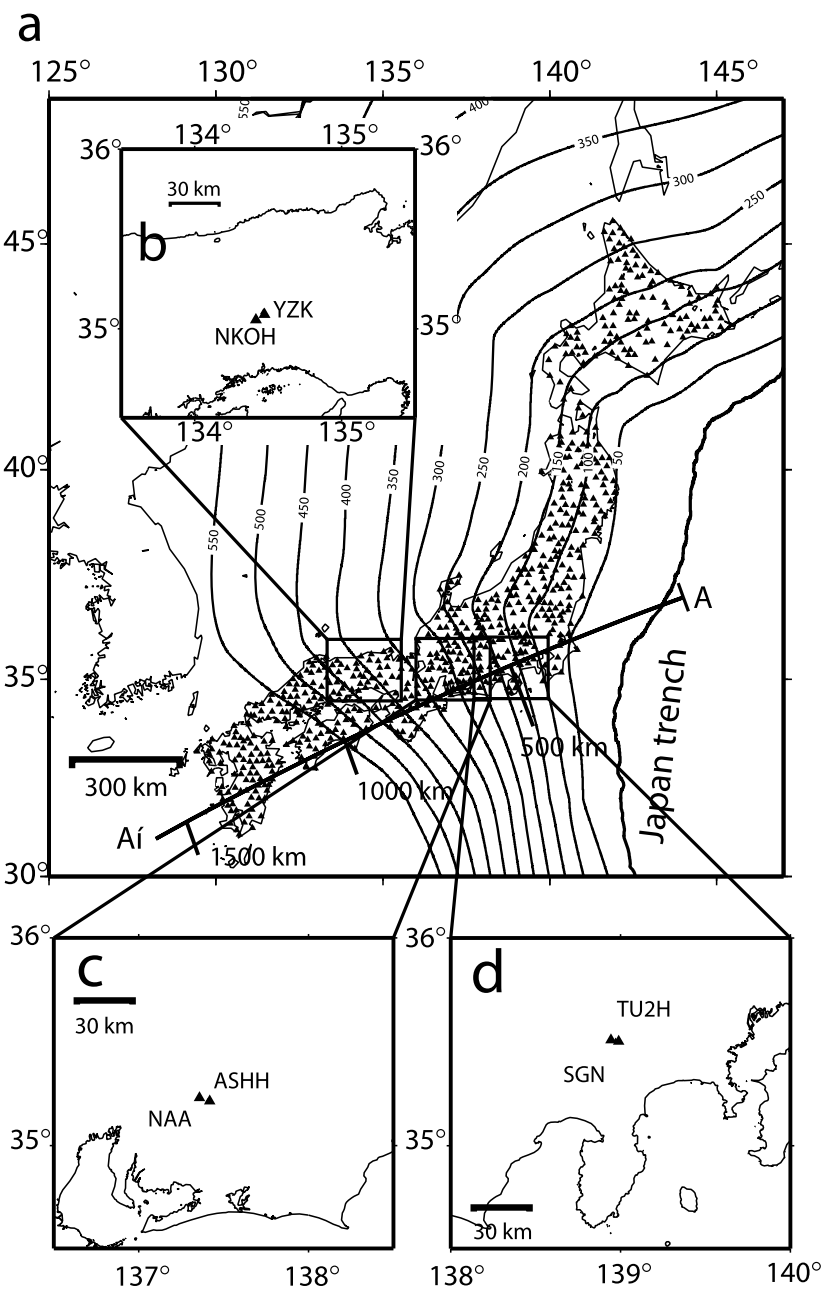

Fig. 1. (a) Triangles represent the Hi-net tiltmeter stations used in this study. Contours (in $\mathrm{km}$ ) denote the depths of the slab surface of the Pacific plate obtained from the distribution of deep and intermediate-deep earthquakes by Zhao et al. (1994). Line A-A' indicates the location of the profile, and the line at the right end of Line A- $\mathrm{A}^{\prime}$ shows the width of the cross section, $\pm 40 \mathrm{~km}$. (b) Two triangles indicate the YZK of the F-net broadband network and the NKOH of the Hi-net tiltmeter network. (c) As for Fig. 1(b), but for the NAA of the F-net and ASHH of the tiltmeter. (d) As for Fig. 1(b), but for the SGN of the F-net and the TU2H of the tiltmeter.

\section{Data}

We examined waveforms from a total of 124 teleseismic events with $\mathrm{Mw} \geq 5.5$ that occurred during the period from April 2003 to May 2004. A total of 675 tiltmeter stations were used in this study (Fig. 1), and more than 46,000 RFs with a good SN ratio were obtained over the network. The original tiltmeter data provided by NIED was in tilt angles (in radians) for the NS and EW directions, with a sampling rate of $20 \mathrm{~Hz}$. We produced horizontal accelerations by multiplying the tilt angles by $-g$ ( $g$ : gravitational constant and $\left.9.8 \mathrm{~m} / \mathrm{s}^{2}\right)$.

\section{Method}

\subsection{Comparison of the waveforms}

To use a tiltmeter recording as a seismogram, we need to examine whether the tiltmeter recording is similar to that of the broadband in the same frequency band. Because the tiltmeter recording is provided as an acceleration seismo-
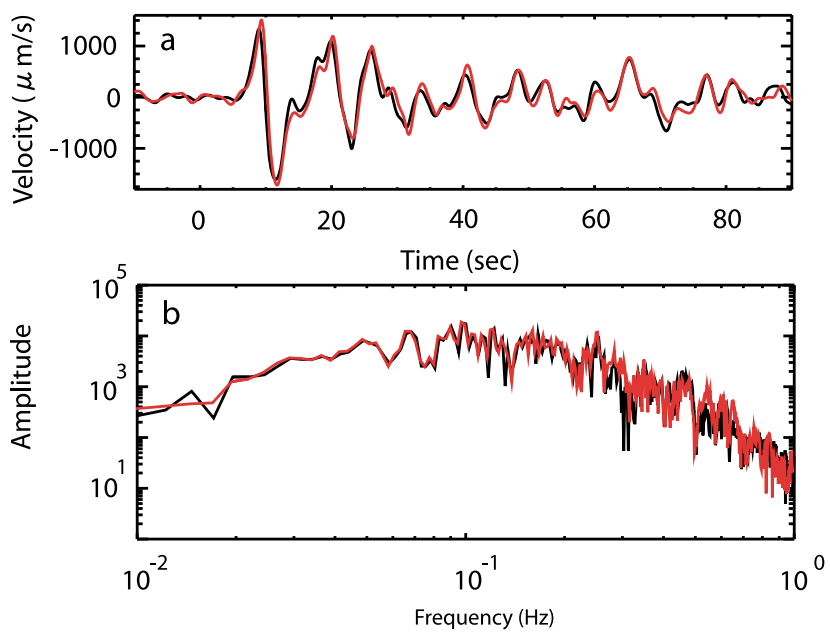

Fig. 2. (a) Comparison of the radial component velocity waveforms observed at the tiltmeter and broadband stations. Band limit is 0.02-0.16 $\mathrm{Hz}$. Red and black lines show tiltmeter recordings observed at $\mathrm{NKOH}$ and a broadband recording observed at YZK [Fig. 1(b)], respectively, for an event that occurred at 21:21 (UT), May 13, 2003, with the hypocenter at $17.3^{\circ} \mathrm{S}, 167.7^{\circ} \mathrm{E}$, at a depth of $33.0 \mathrm{~km}$, Vanuatu Islands. (b) Amplitude spectra corresponding to Fig. 2(a); tiltmeter (red) and broadband seismogram (black).

gram, we first integrated it to generate a velocity seismogram. Basically, tiltmeter recordings have a flat response, even at an extremely lower frequency in acceleration. If lower frequency signals are included in the tiltmeter recordings, the integration from acceleration to velocity would become unstable. Therefore, before the integration, we applied a high-pass filter of $0.02 \mathrm{~Hz}$ to the tiltmeter recordings. For broadband seismograms, we used recordings obtained at a nearby F-net station operated by NIED. In Fig. 1(b), we show the location of the two stations, tiltmeter station $\mathrm{NKOH}$ and broadband station YZK, which we chose in our calibration. The distance between the two stations is approximately $4 \mathrm{~km}$ (Shiomi et al., 2003). Different frequency bands $(0.02-1.0 \mathrm{~Hz}, 0.02-0.3 \mathrm{~Hz}, 0.02-0.16 \mathrm{~Hz}$ and $0.02-$ $0.1 \mathrm{~Hz}$ ) were used to investigate the best bands that show the greatest similarity. We found very similar waveforms in velocity between the two if we used the last two bands, $0.02-0.16 \mathrm{~Hz}$ and $0.02-0.1 \mathrm{~Hz}$. As an example, for $0.02-$ $0.16 \mathrm{~Hz}$ band, we show the comparisons of radial component velocity waveforms in Fig. 2(a), and the corresponding spectra in Fig. 2(b). These comparisons indicate that tiltmeter and broadband recordings have similar instrument responses at the frequency band, thereby implying that instrument response for the tiltmeter can be removed approximately through deconvolution by the stacked vertical component, including instrument response for the broadband.

\subsection{Construction of the source-time function}

Since a tiltmeter records only the horizontal motions, we need to use other types of records to generate source-time functions for deconvolution. To this end we constructed source-time functions for each teleseismic event by stacking all of vertical components obtained by the F-net broadband stations in the Japanese Islands; that is, we consider this stacked waveform as the source-time function for the event (Langston and Hammer, 2001). Because we used 


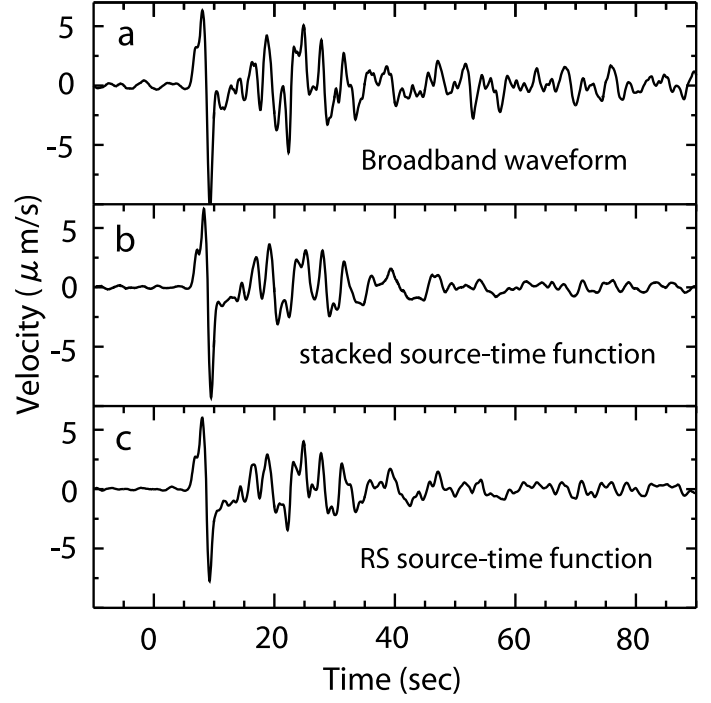

Fig. 3. (a) A vertical broadband seismogram at YZK [Fig. 1(b)] for the same event as that in Fig. 2. (b) A source-time function calculated by stacking 56 vertical broadband recordings. (c) Regional stacked (RS) source-time functions calculated by stacking 17 vertical recordings that are observed at broadband stations within a $300-\mathrm{km}$ radius of $\mathrm{NKOH}$.

the $0.16-\mathrm{Hz}$ low-pass filtered RF, the source-time functions stacked with all vertical components in the Japanese Islands might not be affected by biases induced by local structure. However, it is necessary to examine whether we need to use regional stacked source-time functions to produce $0.16-\mathrm{Hz}$ low-pass filtered RF. Moreover, tiltmeter recordings in the higher frequency band may also be available if we deconvolve with regional stacked source-time functions. Therefore, we also constructed regional stacked source-time functions by stacking vertical seismograms that were observed at broadband stations located within a $300-\mathrm{km}$ radius of a tiltmeter station. When stacking the broadband seismograms, we took the cross correlation to account for moveout across the network. An example of the vertical component observed at YZK, the stacked source-time function, and regional stacked source-time function are shown in Fig. 3(a)(c).

\subsection{Calculation of the receiver function}

Based on the comparisons described in the previous section, we decided to set the low-pass filter to $0.16 \mathrm{~Hz}$ when producing the RFs from the tiltmeter recordings. In addition, we produced $0.3-\mathrm{Hz}$ low-pass filtered RFs deconvolved by regional stacked source-time functions. RFs were calculated through frequency domain division of tiltmeter recordings by stacked source-time functions with a water level of 0.05 and low-pass Gaussian filter. Under these conditions, the stacked source-time functions for frequencies lower than $0.01 \mathrm{~Hz}$ tend to be suppressed, as shown in Fig. 3, because the pulsation is likely to be suppressed by stacking the waveforms obtained in the Japanese Islands. Therefore, we need to use a large value for the water level compared to those applied in previous studies (e.g. Langston, 1979). For comparison, we show four examples of receiver function for low-pass filtering of $0.3 \mathrm{~Hz}$ [Figs. 4(a)-(d)] and 0.16 Hz [Figs. 4(e)-(h)]. We also confirmed whether we can apply a low-pass filter of $0.16 \mathrm{~Hz}$ to waveforms obtained at the other stations in complex tectonic regions and with the other events by comparing RFs (Fig. 5).

\subsection{Stacked RF image in cross-section}

Assuming all later phases of the direct $P$ wave are the $P s$ phases converted at depth, we migrated the time domain RF to the depth domain RF using the IASP91 velocity model (Kennett and Engdahl, 1991). To make a transect, we followed the methodology of previous RF studies with CCP (common conversion point) stacking. We used a cell size of $1 \times 1 \times 10 \mathrm{~km}$ and two widths of $\pm 40 \mathrm{~km}$ and $\pm 100 \mathrm{~km}$ from the line of the cross-section. See Yamauchi et al. (2003) and Tonegawa et al. (2005) for a detailed explanation of the above analysis.
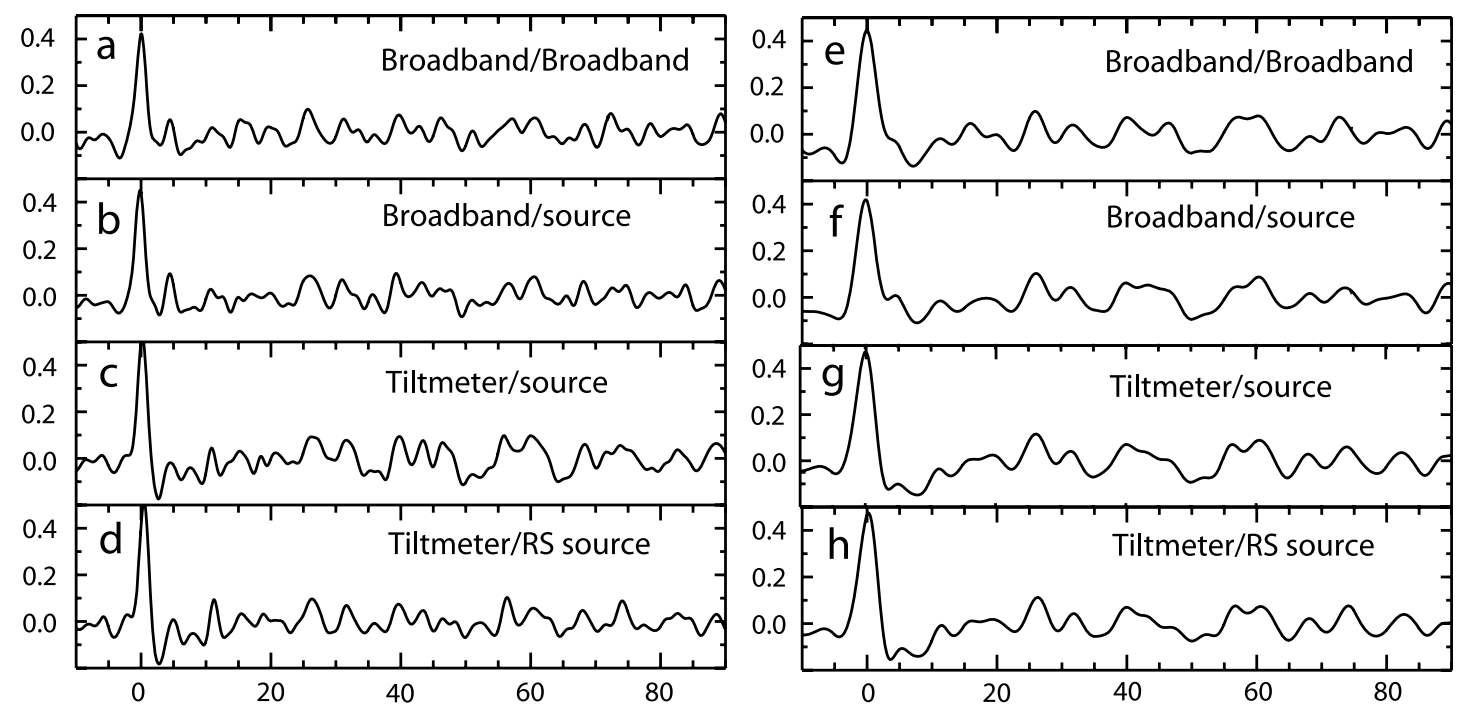

Fig. 4. Four types of $0.3-\mathrm{Hz}$ low-pass filtered RF for: (a) the radial component at YZK deconvolved by the vertical component at YZK, (b) the radial component at YZK by the stacked source-time function, (c) the radial component at NKOH (tiltmeter) by the stacked source-time function, (d) the radial component at NKOH (tiltmeter) by the regional stacked (RS) source-time function. (e)-(h) Same as (a)-(d), but for the 0.16-Hz low-pass filtered RF. These waveforms are calculated for the same event as described in Fig. 2. 


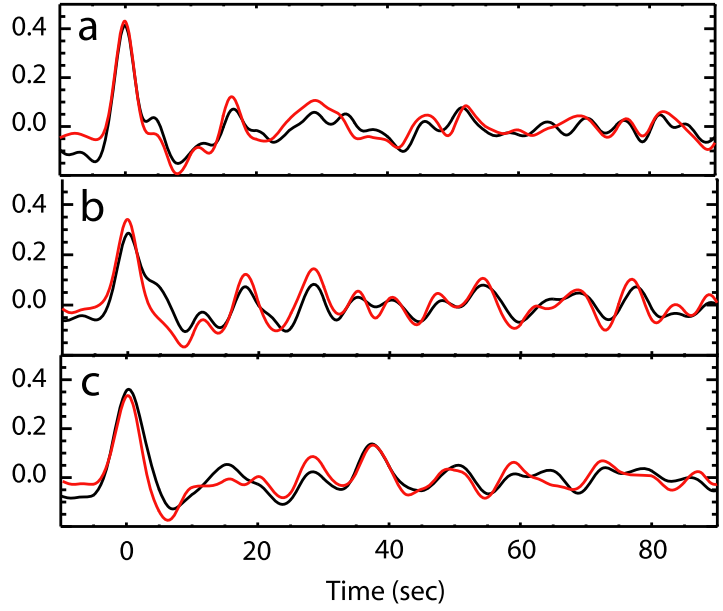

Fig. 5. (a) 0.16-Hz low-pass filtered RFs obtained at ASHH (red) and NAA (black) [Fig. 1(c)]. The distance between these stations is approximately $4 \mathrm{~km}$. (b) $0.16-\mathrm{Hz}$ low-pass filtered RFs obtained at ASHH (red) and NAA (black) [Fig. 1(c)], but for the other event that occurred at 20:26 (UT), November 22,2004 (hypocenter, $46.6^{\circ} \mathrm{S}, 164.7^{\circ} \mathrm{E} ; 10.0$ $\mathrm{km}$ in depth). (c) $0.16-\mathrm{Hz}$ low-pass filtered RFs obtained at TU2H (red) and SGN (black) [Fig. 1(d)] for the same event as in Fig. 5(b). Distance between these stations is approximately $2 \mathrm{~km}$. (Red and black show RFs for tiltmeter and broadband stations, respectively).

\section{Results}

Figure 6 shows the stacked RFs applied $0.16-\mathrm{Hz}$ lowpass filter for the profile $\mathrm{A}-\mathrm{A}^{\prime}$ shown in Fig. 1. The red color represents a positive RF amplitude, indicating velocity increase with depth (e.g. continental and oceanic Moho), while blue represents a negative RF one, indicating velocity decrease downwards (e.g. top slab surface, lower slab boundary). The size of the RF image is $1,600 \times 900 \mathrm{~km}$. Despite the depth of $900 \mathrm{~km}$ and the narrow width of \pm 40 $\mathrm{km}$ from the line of the RF image [Fig. 6(a)], there are enough ray paths to image the upper mantle, and the image is greatly improved in comparison to that of $\pm 200 \mathrm{~km}$ used in the broadband analysis of Tonegawa et al. (2005). Here, in the $0.16-\mathrm{Hz}$ low-pass filtered RF, the detectable thickness of seismic discontinuity is approximately $15 \mathrm{~km}$; it is $7 \mathrm{~km}$ in a $0.3-\mathrm{Hz}$ low-pass filtered RF described in a following section.

In the Japan subduction zone, the Pacific slab extends from the surface to around or below the 660, as suggested by a recent tomographic study (Fukao et al., 2001). Our RF image suggests that the oceanic Moho within the subducting slab can be seen to depth of $400 \mathrm{~km}$ by positive RF amplitude, and the lower slab boundary is also detected down to a depth of $600 \mathrm{~km}$ by negative dipping RF amplitudes [Figs. 6(a) and (b)]. Based on such a depth difference in appearance, negative amplitudes are not due to side lobes of the bandpass filter used in the seismic processing. Although the imaging of the Pacific plate down to a depth of $200 \mathrm{~km}$ has been reported in a previous study using broadband data (Tonegawa et al., 2005), those of the oceanic Moho and the lower slab boundary reaching the transition zone have never been reported and are presented for the first time here. The 410 and the 660 are also detected and show undulation in positive RF amplitude. The uplifted and the depressed part of them affected by the descending slab can also be seen
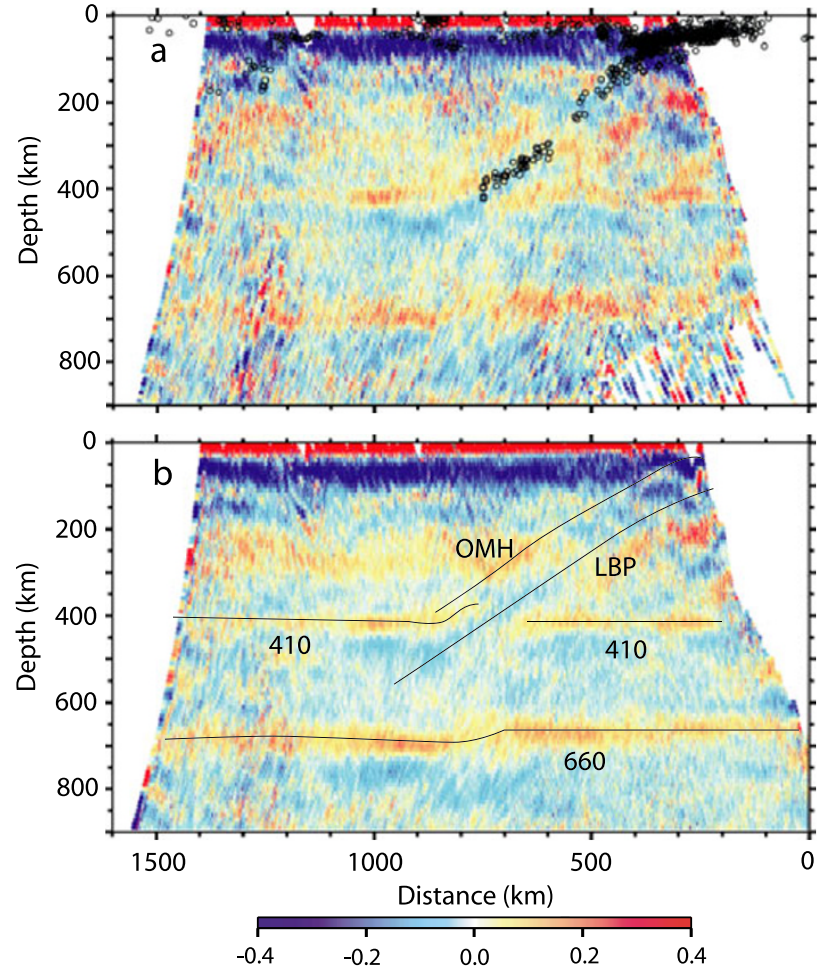

Fig. 6. Stacked images, $1,600 \times 900 \mathrm{~km}$, at $\mathrm{A}-\mathrm{A}^{\prime}$ for $0.16-\mathrm{Hz}$ low-pass Gaussian filtered RFs. (a) RF image with a width of $\pm 40 \mathrm{~km}$ with earthquake hypocenters. (b) RF image with a width of $\pm 100 \mathrm{~km}$ and with its interpretation: OMH, the oceanic Moho inside the Pacific slab; LBP, the lower boundary of the Pacific slab; 410, the $410 \mathrm{~km}$ discontinuity; 660, the $660 \mathrm{~km}$ discontinuity.

in the cross-sections [Figs. 6(a) and (b)] and topographical maps [Figs. 7(a) and (b)] that were calculated by following Tonegawa et al. (2005), as reported by previous studies focusing on the Japan subduction zone (e.g. Collier and Helffrich, 1997; Tonegawa et al., 2005; Tono et al., 2005).

\section{Discussion}

\subsection{Tiltmeter recordings as broadband seismograms}

Figures 4(e)-(h) show that the four types of RFs are almost the same in the waveform shape, implying that tiltmeter recordings can be substituted for broadband seismograms in this frequency band (lower than $0.16 \mathrm{~Hz}$ ). For the higher frequency bands (e.g. lower than 0.3 or $1.0 \mathrm{~Hz}$ ), although the waveforms were similar with respect to both the locations of the peaks (e.g. $P s$ phases) and amplitudes, especially for frequencies lower than $0.3 \mathrm{~Hz}$ [Figs. 4(a)-(d)], the waveform in Fig. 4(c) was slightly different from that in Fig. 4(d). This indicates that the $0.3-\mathrm{Hz}$ low-pass filtered RF deconvolved by the source-time function, which is obtained by stacking all vertical seismograms over the network, seems to be affected by local structure while the 0.16 $\mathrm{Hz}$ low-pass filtered RF is presumably not affected. Indeed, remarkable traces of $P S$ phase shown in Fig. 6 are also clearly seen in the imaging with $0.3-\mathrm{Hz}$ low-pass filtered RFs (Fig. 8), which are deconvolved by regional stacked source-time functions.

However, the continental Moho cannot be seen even with the $0.3-\mathrm{Hz}$ low-pass filtered RF because large negative amplitudes appear following $P$-arrival in RF calculated with 

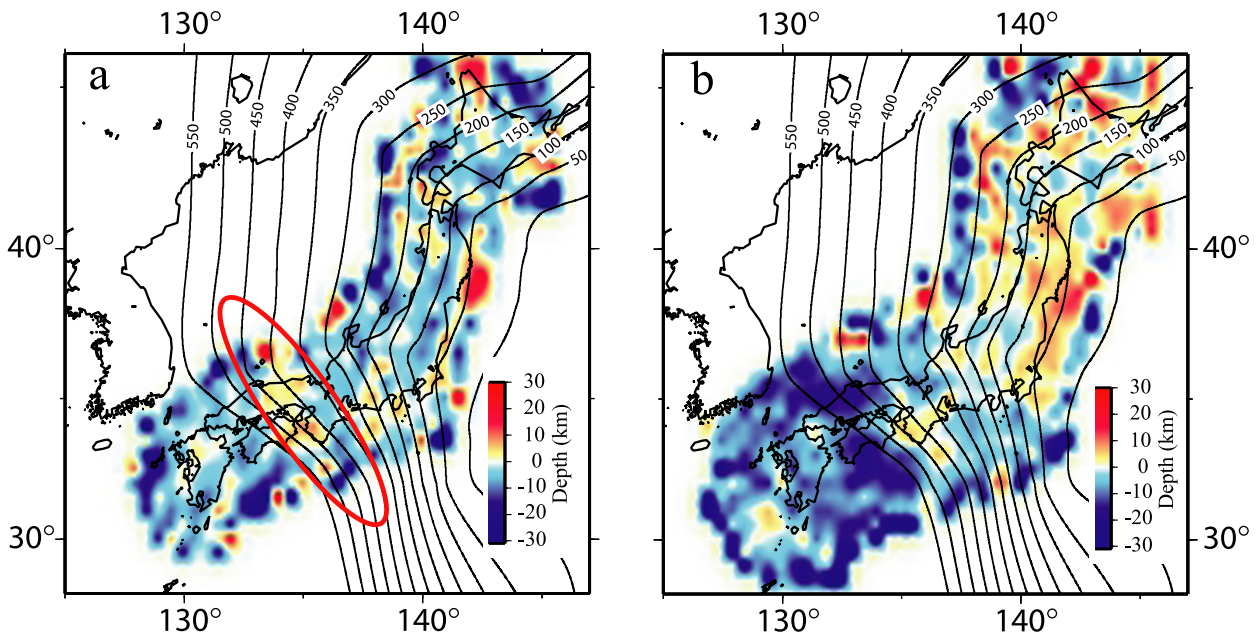

Fig. 7. Topographical contour maps of the 410 and the 660 calculated for $0.16-\mathrm{Hz}$ low-pass filtered RFs. (a) Depth variations of 410 for $0.16-\mathrm{Hz}$ low-pass filtered RFs. Colors indicate the depth differences from $410 \mathrm{~km}$. Red to yellow indicates the elevation, and pale-blue to blue one indicates depression. The red circle shows the uplift portion of the 410. (b) Same as in Fig. 7(a), but for the depth variations of the $660 \mathrm{~km}$ discontinuity from $670 \mathrm{~km}$.

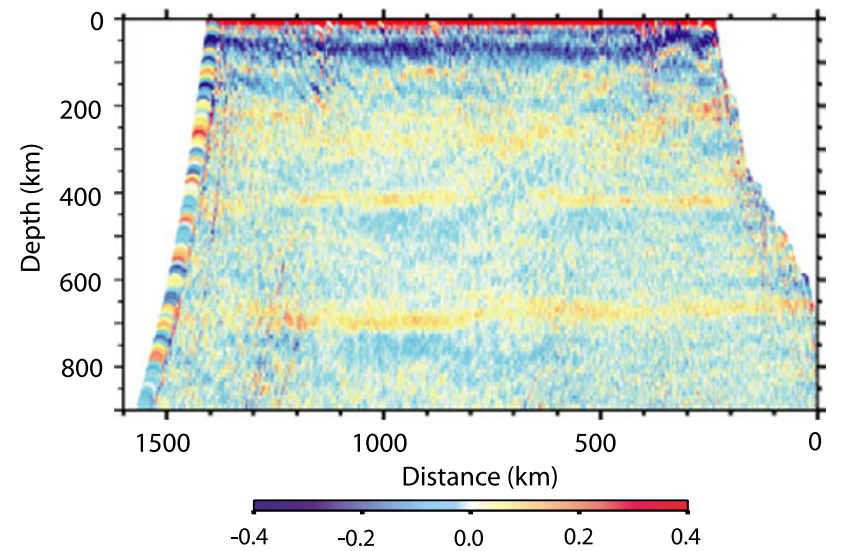

Fig. 8. Stacked images, $1,600 \times 900 \mathrm{~km}$, at A-A' with a width of $\pm 40 \mathrm{~km}$ for $0.3-\mathrm{Hz}$ low-pass Gaussian filtered RFs. These RFs are produced by deconvolving with regional stacked source-time functions. tiltmeter recording [Fig. 4(d) and (g)]. There are two possible reasons for such negative phases. One is water level and the other is high-pass filter before integration. For the water level, however, Fig. 9(a) shows that different values of water level would not greatly affect waveform shape, implying that those negative phases are not produced by a large value of water level. For high-pass filtering, as shown in Fig. 9(b), we found such negative amplitudes disappear if we maintain the lower frequencies up to $0.005 \mathrm{~Hz}$ before integrating from acceleration to velocity, indicating that they are presumably produced by a lack of lower frequencies. In this study, however, we choose a high-pass filter of $0.02 \mathrm{~Hz}$ for the following two reasons: (1) if we apply a high-pass filter of $0.005 \mathrm{~Hz}$ to the recordings from the other events to remove negative amplitudes, some of these recordings will be unstable in integration; (2) it seems that a lack of lower frequencies affects waveform shape, but only just around the direct $P$ wave [Fig. 9(b)]. This defection should be improved if we investigate the structure in the crust and the uppermost mantle.

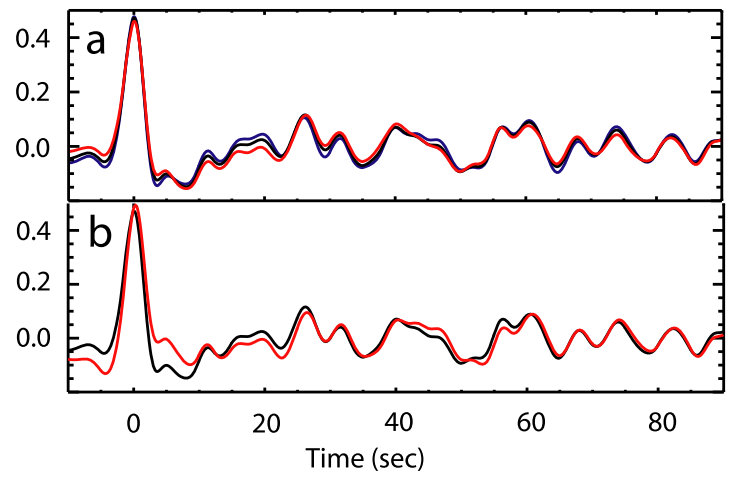

Fig. 9. (a) Three $0.16-\mathrm{Hz}$ low-pass filtered RFs with different water levels: blue line, 0.10; black line, 0.05 [same as Fig. 4(g)]; red line, 0.01. (b) Two 0.16-Hz low-pass filtered RFs calculated by tiltmeter recordings with different frequency bands: black line, $0.02-0.16 \mathrm{~Hz}$ [same as Fig. 4(g)]; red line, 0.005-0.16 Hz.

\subsection{Upper mantle discontinuities and the subducting slab}

Why does the positive RF amplitude of the oceanic Moho disappear in the transition zone? As seen in Fig. 5, the oceanic Moho can be traced down to a depth of $400 \mathrm{~km}$, terminating below the 410 , while the lower slab boundary can be imaged by remarkable negative RF amplitudes down to a depth of $600 \mathrm{~km}$. The dipping oceanic Moho should be traced in the transition zone if a sharp velocity contrast is retained there because the lower slab boundary with the almost same dip angle as that of the oceanic Moho can be imaged there. The possible reason for such a termination is that the slab surface is a complex structure by the stagnating process of the slab above the 660. This suggestion is in good agreement with the results of the tomographic survey around the Japanese Islands (Fukao et al., 2001).

Moreover, which discontinuity for the subducting slab does the dipping positive RF amplitude in our result indicate? Because the uppermost portion of the Pacific plate consists of the oceanic crust, which has a low velocity com- 
pared to both the overriding mantle and the oceanic mantle, the downward velocity jump corresponding to the slab surface is described by negative RF amplitude. On the other hand, basalt in the oceanic crust would be metamorphosed to eclogite at depths of 80-130 km (Yuan et al., 2000; Ferris et al., 2003; Hacker et al., 2003b), which cannot be seismically distinguishable with respect to mantle peridotite. Therefore, the negative phase would disappear below the depth of its transformation, and hence the dipping positive phase corresponding to the oceanic Moho would be isolated. In this study, the oceanic Moho can be detected by positive phases down to a depth of $400 \mathrm{~km}$, while the oceanic crust above its transformation depth cannot be detected because of the low resolution of the RF. However, the oceanic Moho and the lower slab boundary are consistent with the hypocenter distribution in Fig. 6(a). Moreover, since the seismic velocity contrast among overriding mantle peridotite, eclogite of the oceanic crust and underlying peridotite in the upper mantle possibly vary based on whether those phases are metamorphosed before or during the subducting process (Hacker et al., 2003a), it is possible that the positive phase corresponds to the slab surface. To be able to discuss in more detail to which discontinuity the positive RF amplitude in our result corresponds, we need to await the results of future seismological, theoretical and experimental investigations showing the subduction process down to a depth of at least $410 \mathrm{~km}$.

The 660 is also depressed down to a depth of $700 \mathrm{~km}$ in the region where the lower slab boundary does not reach the $660(700-800 \mathrm{~km}$ in horizontal axis in Figs. 6(a) and (b)), and its downward returns up to $680 \mathrm{~km}$ depth $(1,000-$ $1,500 \mathrm{~km}$ in horizontal axis in Figs. 6(a) and (b)). The cold thermal anomaly associated with the subducting slab seems to expand relatively large area and affect the distortion of the 660, even if the subducting slab does not reach the 660 .

\section{Conclusion}

We report that Hi-net tiltmeter recordings are available for imaging the upper mantle discontinuities in the Japan subduction zone. The tiltmeter recordings are very similar to the broadband seismograms at a frequency band between 0.02 and $0.16 \mathrm{~Hz}$. If we use regional stacked sourcetime functions for deconvolution, the tiltmeter recordings at a frequency band between 0.02 and $0.3 \mathrm{~Hz}$ can also be available to the image upper mantle structure. The tiltmeter RF image shows that the oceanic Moho and the lower slab boundary can be detected down to a depth of 400 and 600 $\mathrm{km}$, thus realizing one of the highest quality images for subducting slab. Moreover, the upward and downward undulation of the 410 and the 660 affected by the cold interior of the descending slab are also traced much more clearly than has been possible in previous RF studies.

Acknowledgments. We thank X. Yuan, H. Gilbert and one anonymous reviewer for reviewing our manuscript. We are also grateful to F. Niu and Editor E. Fukuyama for their helpful com- ments that greatly improved the manuscript. We used a software package, GMT, to draw maps (Wessel and Smith, 1999). This study was funded by a Research Fellowship of the Japan Society for the Promotion of Science (JSPS) for Young Scientists and by Grand-in-Aid for Scientific Research (B) (17340130) of MEXT.

\section{References}

Collier, J. D. and G. R. Helffrich, Topography of the " 410 " and " 660 " km seismic discontinuities in the Izu-Bonin subduction zone, Geophys. Res. Lett., 24, 1535-1538, 1997.

Ferris, A., G. A. Abers, D. H. Christensen, and E. Veenstra, High resolution image of the subducted Pacific plate beneath central Alaska, 50-150 km depth, Earth Planet. Sci. Lett., 214, 575-588, 2003.

Fukao, Y., S. Widiyantoro, and M. Obayashi, Stagnant slabs in the upper and lower transition region, Rev. Geophys., 39, 291-323, 2001.

Hacker, B. R., A. A. Geoffrey, and S. M. Peacock, Subduction factory; 1. Theoretical mineralogy, densities, seismic wave speeds, and $\mathrm{H}_{2} \mathrm{O}$ contents, J. Geophys. Res., 108, 2029, 2003a.

Hacker, B. R., S. M. Peacock, G. A. Abers, and S. D. Holloway, Subduction factory; 2. Are intermediate-depth earthquakes in subducting slabs linked to metamorphic dehydration reaction?, J. Geophys. Res., $\mathbf{1 0 8}$, 2003 b.

Hori, S, Performance of tiltmeters as long period seismographs equipped at the Hi-net stations, ABSTRACTS 2002 Japan Earth and Planetary Science Joint Meeting, S045-P010, 2002.

Kennett, B. L. N. and E. R. Engdahl, Travel times for global earthquake location and phase identification, Geophys. J. Int., 105, 429-465, 1991.

Langston, C. A., Structure under Mount Rainier, Washington, inferred from teleseismic body waves, J. Geophys. Res., 84, 4749-4762, 1979.

Langston, C. A. and J. K. Hammer, The vertical component P-wave receiver function, Bull. Seismol. Soc. Am., 91, 1805-1819, 2001.

Li, X., S. V. Sobolev, R. Kind, X. Yuan, and Ch. Estabrook, A detailed receiver function image of the upper mantle discontinuities in the Japan subduction zone, Earth Planet. Sci. Lett., 183, 527-541, 2000.

Ramesh, D. S., H. Kawakatsu, S. Watada, and X. Yuan, Receiver function images of the central Chugoku region in the Japanese islands using Hinet data, Earth Planets Space, 57, 271-280, 2005.

Ringwood, A. E., Composition and Petrology of the Earth's Mantle, McGraw-Hill, New York, 1975.

Shiomi, K., K. Obara, S. Aoi, and K. Kasahara, Estimation on the azimuth of the Hi-net and KiK-net borehole seismimeters, Zisin2, 56, 99-110, 2003 (in Japanese).

Tonegawa, T., K. Hirahara, and T. Shibutani, Detailed structure of the upper mantle discontinuities around the Japan subduction zone imaged by receiver function analyses, Earth Planets Space, 57, 5-14, 2005.

Tono, Y., T. Kunugi, Y. Fukao, S. Tsuboi, K. Kanjo, and K. Kasahara, Mapping of the 410 -and $660-\mathrm{km}$ discontinuities beneath the Japanese islands, J. Geophys. Res., 110(B3), B03307, doi: 10.1029/2004JB003266, 2005

Wessel, P. and W. H. F. Smith, Free software helps maps and display data, Abst. Eos Trans., AGU, 72, 445-446, 1999.

Yamauchi, M., K. Hirahara, and T. Shibutani, High-resolution receiver function imaging of the seismic velocity discontinuities in the crust and the uppermost mantle beneath southwest Japan, Earth Planets Space, 55, 59-64, 2003.

Yuan, X., S. V. Sobolev, R. Kind, O. Oncken, G. Bock, G. Asch, B. Schurr, F. Graeber, A. Rudloff, W. Hanka, K. Wylegalla, R. Tibi, C. Haberland, A. Rietbrock, P. Giese, P. Wigger, P. Rower, G. Zandt, S. Beck, T. Wallace, M. Pardo, and D. Comte, Subduction and collision processes in the Central Andes constrained by converted seismic phases, Nature, 408, 958-961, 2000.

Zhao, D., A. Hasegawa, and H. Kanamori, Deep structure of Japan subduction zone as derived from local, regional and teleseismic events, $J$. Geophys. Res., 99, 22313-22329, 1994.

T. Tonegawa (e-mail: tonegawa@eps.nagoya-u.ac.jp), K. Hirahara, T. Shibutani, and K. Shiomi 